\title{
Novel biomarkers for prediabetes, diabetes, and associated complications
}

This article was published in the following Dove Press journal: Diabetes, Metabolic Syndrome and Obesity:Targets and Therapy 14 August 2017

Number of times this article has been viewed

\author{
Brenda Dorcely' \\ Karin Katz' \\ Ram Jagannathan ${ }^{2}$ \\ Stephanie S Chiang' \\ Babajide Oluwadare' \\ Ira J Goldberg' \\ Michael Bergman' \\ 'New York University School of \\ Medicine, Department of Medicine, \\ Division of Endocrinology, Diabetes \\ and Metabolism, NYU Langone \\ Medical Center, New York, NY, \\ ${ }^{2}$ Department of Global Health, Rollins \\ School of Public Health, Emory \\ University, Atlanta, GA, USA
}

Correspondence: Michael Bergman New York University School of Medicine, Division of Endocrinology, Diabetes and Metabolism, NYU Langone Medical Center, 550 Ist Avenue, Suite 5E, New York, NY 10016, USA

Tel + I $21248 \mid 1350$

Fax + I $21248 \mid$ I355

Email michael.bergman@nyumc.org

\begin{abstract}
The number of individuals with prediabetes is expected to grow substantially and estimated to globally affect 482 million people by 2040 . Therefore, effective methods for diagnosing prediabetes will be required to reduce the risk of progressing to diabetes and its complications. The current biomarkers, glycated hemoglobin (HbA1c), fructosamine, and glycated albumin have limitations including moderate sensitivity and specificity and are inaccurate in certain clinical conditions. Therefore, identification of additional biomarkers is being explored recognizing that any single biomarker will also likely have inherent limitations. Therefore, combining several biomarkers may more precisely identify those at high risk for developing prediabetes and subsequent progression to diabetes. This review describes recently identified biomarkers and their potential utility for addressing the burgeoning epidemic of dysglycemic disorders.

Keywords: prediabetes, biomarkers, inflammatory markers, diabetes, diabetes complications
\end{abstract}

\section{Introduction}

Prediabetes is defined as an intermediate state with plasma glucose levels ranging between normoglycemia and diabetes. The Centers for Disease Control estimated that in 2012 about 86 million, or one out of three, adults had prediabetes in the US. ${ }^{1}$ However, $90 \%$ of these individuals were unaware of their diagnosis. In 2015 , the International Diabetes Federation estimated that the worldwide prevalence of impaired glucose tolerance (IGT) in adults was 318 million and expected to reach 482 million by $2040 .^{2}$ The annual progression rate to diabetes is $5-10 \%,{ }^{3}$ with older individuals, those with severe insulin resistance (IR), low insulin secretion, and other diabetes risk factors even more likely to progress. ${ }^{4}$ How can we identify patients with prediabetes and what can we do to prevent progression to diabetes?

Lifestyle and pharmacological interventions have been most effective in preventing progression to diabetes and associated complications. Preservation of $\beta$-cell function and reduction in IR and diabetes complications such as retinopathy, cardiovascular disease (CVD), and all-cause mortality were observed subsequent to lifestyle modification. ${ }^{5,6}$ The Da Qing Diabetes Study in China, ${ }^{6}$ the Finnish Diabetes Prevention Study, ${ }^{7,8}$ and the U.S. Diabetes Prevention Program ${ }^{3,9}$ have shown that changes in dietary habits, weight loss, and increased physical activity reduced the risk of progression to diabetes. Bariatric surgery promotes weight loss and is beneficial in prediabetes. ${ }^{10}$

\section{Identification of risk and diagnosis of prediabetes}

Development of prediabetes involves multiple factors including genetics, peripheral IR, defects in insulin secretion, glucotoxicity, lipotoxicity, impaired incretin release, 
amylin accumulation, inflammation, oxidative stress, and decreased $\beta$-cell mass leading to $\beta$-cell dysfunction. ${ }^{11-13}$ Prediabetes is classified as isolated impaired fasting glucose (IFG) or IGT. ${ }^{14}$ Glucose and glycated hemoglobin (HbA1c) criteria for diagnosing dysglycemic states are controversial as there are differing thresholds recommended by the American Diabetes Association (ADA) and the World Health Organization. ${ }^{15,16}$ We will review several additional biomarkers used to predict the risk of progression to diabetes.

\section{Diagnostic biomarkers and their clinical utility Hemoglobin Alc}

HbA1c is the most commonly used biomarker to diagnose prediabetes and diabetes. HbAlc forms when glucose attaches to the amino-terminal group of the $\beta$ subunit of hemoglobin. ${ }^{17} \mathrm{HbA} 1 \mathrm{c}$ reflects chronic glycemia rather than glucose levels at a single time point. Currently, the ADA criteria for diabetes are $\mathrm{HbA} 1 \mathrm{c} \geq 6.5 \%(48 \mathrm{mmol} / \mathrm{mol})$ and $5.7-6.4 \%$ (39-46 $\mathrm{mmol} / \mathrm{mol})$ for prediabetes. ${ }^{14}$ Increased HbA1c levels are associated with increased morbidity and mortality. In the Norfolk prospective study, higher HbA1c levels were also associated with increased CVD, cancer, and all-cause mortality. ${ }^{18}$ Long-term prospective studies, including the Diabetes Control and Complications Trial, the UK Prospective Diabetes Study Group, and the Epidemiology of Diabetes Interventions and Complications study have shown that diabetic complications are directly related to the mean HbA1c, with a level $\geq 6.5 \%$ (48 $\mathrm{mmol} / \mathrm{mol})$ associated with retinopathy. ${ }^{19-21}$ Additionally, HbA1c was more strongly correlated with retinopathy than fasting plasma glucose (FPG). Thus, HbA1c may be a better predictor of microvascular complications than FPG. ${ }^{22}$

$\mathrm{HbA} 1 \mathrm{c}$ has several advantages versus FPG and oral glucose tolerance test (OGTT) including greater convenience as fasting is not required, greater pre-analytical stability, and less day-to-day perturbation during periods of stress and illness. ${ }^{23}$ Since $\mathrm{HbA} 1 \mathrm{c}$ reflects chronic exposure to glucose, it is particularly useful for lifestyle modification counseling. ${ }^{23,24}$ However, there is conflicting evidence regarding the usefulness of $\mathrm{HbA} 1 \mathrm{c}$ as it provides moderate sensitivity in diabetes diagnosis when compared to OGTT and FPG (Table 1). ${ }^{23,24}$ OGTT is more strongly correlated with IR and secretion than $\mathrm{HbA} 1 \mathrm{c},{ }^{25}$ which is expected since the response to a high dose of glucose would more accurately reflect an individual's physiologic response and insulin secretion and actions. For

Table I Characteristics of biomarkers for prediabetes, diabetes, and associated complications

\begin{tabular}{|c|c|c|c|c|c|}
\hline \multicolumn{6}{|c|}{ Traditional biomarkers } \\
\hline Biomarker & $\begin{array}{l}\text { Mechanism of } \\
\text { action }\end{array}$ & $\begin{array}{l}\text { Sensitivity and } \\
\text { specificity }\end{array}$ & Advantages & Disadvantages & $\begin{array}{l}\text { Association with } \\
\text { dysglycemia }\end{array}$ \\
\hline I. HbAlc & $\begin{array}{l}\text { HbAlc forms } \\
\text { when glucose } \\
\text { attaches to the } \\
\text { amino-terminal } \\
\text { group of the } \\
\beta \text { subunit of } \\
\text { hemoglobin }{ }^{17}\end{array}$ & $\begin{array}{l}\text { Diabetes }^{28} \\
\text { When HbAlc } \geq 6.5 \% \\
\text { compared to FPG } \\
\mathrm{FPG} \geq 126 \mathrm{mg} / \mathrm{dL} \\
(7.0 \mathrm{mmol} / \mathrm{L}) \text { and } \\
2 \text {-hour plasma } \\
\text { glucose } \geq 200 \mathrm{mg} / \mathrm{dL} \\
\text { (I I.I mmol/L) } \\
\text { Sensitivity: } 0.589 \\
\text { Specificity: } 0.960 \\
\text { Prediabetes } \\
\text { HbAlc } \geq 5.7,<6.5 \text { for } \\
\text { prediabetes } \\
\text { Sensitivity: } 0.354 \\
\text { Specificity: } 0.834\end{array}$ & $\begin{array}{l}\text { Increased HbAlc levels } \\
\text { are associated with } \\
\text { increased morbidity and } \\
\text { mortality }{ }^{18} \\
\text { More reliable biomarker } \\
\text { of chronic glycemia } \\
\text { HbAlc correlates with } \\
\text { greater convenience, } \\
\text { greater pre-analytical } \\
\text { stability, and less day- } \\
\text { to-day perturbation } \\
\text { during periods of stress } \\
\text { and illness }{ }^{23}\end{array}$ & $\begin{array}{l}\text { HbAlc has moderate } \\
\text { sensitivity in diagnosing } \\
\text { diabetes when compared to } \\
\text { OGTT and } \text { FPG }^{24-26} \\
\text { No consensus which cut-off } \\
\text { points for HbAlc would be } \\
\text { most sensitive }{ }^{26-29} \\
\text { HbAIc threshold for } \\
\text { prediabetes does not consider } \\
\text { ethnicity, BMl, and age, all of } \\
\text { which may significantly alter } \\
\text { HbAIc levels } \\
\text { HbAlc } \\
\text { measure of average circulating } \\
\text { glucose levels } \\
\text { Changes in the production } \\
\text { rate or circulating life span of } \\
\text { red blood cells affect HbAIc } \\
\text { levels, as well as hemoglobin } \\
\text { variants such as HbS, HbC, } \\
\mathrm{HbD} \text {, and HbE }{ }^{36,39}\end{array}$ & $\begin{array}{l}\mathrm{HbAlc} \text { is a reflection } \\
\text { of chronic glycemia }{ }^{17}\end{array}$ \\
\hline
\end{tabular}

(Continued) 
Table I (Continued)

\begin{tabular}{|c|c|c|c|c|c|}
\hline \multicolumn{6}{|c|}{ Traditional biomarkers } \\
\hline Biomarker & $\begin{array}{l}\text { Mechanism of } \\
\text { action }\end{array}$ & $\begin{array}{l}\text { Sensitivity and } \\
\text { specificity }\end{array}$ & Advantages & Disadvantages & $\begin{array}{l}\text { Association with } \\
\text { dysglycemia }\end{array}$ \\
\hline 2. FA & $\begin{array}{l}\text { FA is a ketoamine } \\
\text { created by } \\
\text { glycosylation } \\
\text { of total serum } \\
\text { proteins, primarily } \\
\text { albumin }{ }^{41}\end{array}$ & $\begin{array}{l}\text { Diabetes }^{38} \\
2.5 \text { mmol/L for } \\
\text { diabetes (FPG } \\
>7 \text { mmol/L or } \\
\mathrm{HbAI} \mathrm{c} \geq 6.5 \% \text { ) } \\
\text { Sensitivity: } 0.82 \\
\text { Specificity: } 0.94 \\
\text { Prediabetes }^{38} \\
\text { Limited data }\end{array}$ & $\begin{array}{l}\text { FA reflects average } \\
\text { blood glucose } \\
\text { concentration over the } \\
\text { previous I-4 weeks }{ }^{38} \\
\text { FA is especially } \\
\text { beneficial in conditions } \\
\text { that affect hemoglobin } \\
\text { status or rate of } \\
\text { erythrocyte turnover } \\
\text { FA is cost-effective, } \\
\text { simple, and convenient, } \\
\text { as it does not require } \\
\text { fasting }\end{array}$ & $\begin{array}{l}\text { FA has higher within-subject } \\
\text { variation and falsely low levels } \\
\text { in conditions leading to rapid } \\
\text { albumin turnover }{ }^{44} \\
\text { Not all studies have found } \\
\text { that mean serum FA levels } \\
\text { are useful for prediabetes } \\
\text { screening } \\
37,38,41,47\end{array}$ & $\begin{array}{l}\text { FA increases in } \\
\text { states of high glucose } \\
\text { concentrations }^{41}\end{array}$ \\
\hline 3. GA & $\begin{array}{l}\text { Glycosylation } \\
\text { of albumin and } \\
\text { measured by the } \\
\text { ratio of GA to } \\
\text { total albumin }\end{array}$ & $\begin{array}{l}\text { Diabetes }^{50} \\
\text { When GA is } \geq 15.5 \% \\
\text { Sensitivity: } 0.83 \\
\text { Specificity: } 0.83 \\
\text { Prediabetes }{ }^{49} \\
\text { When GA >I3.35\% } \\
\text { for prediabetes } \\
\text { Sensitivity: } 0.4 \text { I } \\
\text { Specificity: } 0.7 \text { I } \\
\text { The combination of } \\
\text { GA with HbAIc can } \\
\text { predict prediabetes } \\
\text { with greater } \\
\text { sensitivity than } \\
\text { HbAIc alone }{ }^{49}\end{array}$ & $\begin{array}{l}\text { GA is a superior index } \\
\text { of glycemic control } \\
\text { than HbAlc in patients } \\
\text { with renal failure, } \\
\text { hemolytic anemia, and } \\
\text { those receiving blood } \\
\text { transfusions }{ }^{41} \\
\text { GA is preferred over } \\
\text { FA in clinical conditions } \\
\text { that result in protein } \\
\text { loss such as nephrotic } \\
\text { syndrome, liver disease, } \\
\text { and thyroid disease }{ }^{41} \\
\text { GA may be artificially } \\
\text { low in individuals with } \\
\text { increased BMl, body } \\
\text { fat mass, and visceral } \\
\text { adiposity }{ }^{53}\end{array}$ & $\begin{array}{l}\text { Inaccurate when there are } \\
\text { changes in albumin turnover } \\
\text { Falsely lower levels in obesity }{ }^{52}\end{array}$ & $\begin{array}{l}\text { Serum GA is associated } \\
\text { with prediabetes and } \\
\text { diabetes }^{49}\end{array}$ \\
\hline 4. OGTT & $\begin{array}{l}\text { Measures fasting } \\
\text { and 2-hour plasma } \\
\text { glucose levels }\end{array}$ & $\begin{array}{l}\text { Diabetes } \\
\text { Sensitivity: } \\
0.93^{155} \\
\text { Prediabetes } \\
\text { Sensitivity: } \\
0.81^{155}\end{array}$ & $\begin{array}{l}\text { OGTT is more strongly } \\
\text { correlated with IR and } \\
\text { secretion than } \mathrm{HbAIc}^{25} \\
\text { OGTT provides } \\
\text { important information } \\
\text { with regard to risk that } \\
\mathrm{HbAIc} \text { or FPG cannot }{ }^{4}\end{array}$ & $\begin{array}{l}\text { OGTT is variable, invasive, and } \\
\text { time consuming } \\
\text { It is inconvenient because it } \\
\text { requires fasting and shows } \\
\text { day-to-day perturbation during } \\
\text { periods of stress and illness }\end{array}$ & $\begin{array}{l}\text { Elevated FPG and } \\
\text { 2-hour levels are } \\
\text { associated with } \\
\text { prediabetes and } \\
\text { diabetes }\end{array}$ \\
\hline 5. I, 5 AG & $\begin{array}{l}\text { I,5 AG is a dietary } \\
\text { monosaccharide. } \\
\text { Plasma } \\
\text { concentrations } \\
\text { are inversely } \\
\text { correlated with } \\
\text { plasma glucose }^{60}\end{array}$ & $\begin{array}{l}\text { Diabetes }^{47} \\
\text { When I,5 AG }<17 \\
\text { mcg/mL for diabetes } \\
\text { defined by optimal } \\
\text { HbAIc }>6 \% \text { cutoff } \\
\text { Sensitivity: } 0.96 \\
\text { Specificity: } 0.88 \\
\text { Prediabetes } \\
\text { Data not available }\end{array}$ & $\begin{array}{l}\text { I,5 AG is a useful } \\
\text { biomarker as it reflects } \\
\text { glucose levels within the } \\
\text { past 10-14 days } \\
\text { It is stable, replicable, } \\
\text { and less costly } \\
\text { compared to other } \\
\text { glycemic diagnostic } \\
\text { tests }^{61}\end{array}$ & $\begin{array}{l}\text { Plasma I,5 AG levels can } \\
\text { change based on dietary habits, } \\
\text { sex, and race }{ }^{64,65} \\
\text { Levels are also affected } \\
\text { by renal hemodynamics } \\
\text { or treatment with SGLT } \\
\text { inhibitors }{ }^{66,67}\end{array}$ & $\begin{array}{l}\text { Plasma I,5 AG levels } \\
\text { are lowered in subjects } \\
\text { with prediabetes and } \\
\text { diabetes compared } \\
\text { with subjects with } \\
\text { normoglycemia }\end{array}$ \\
\hline
\end{tabular}


Table I (Continued)

\begin{tabular}{ll}
\hline Novel biomarkers & \\
\hline Biomarker & Mechanism of action \\
6. Adiponectin & $\begin{array}{l}\text { Adiponectin is derived from adipose tissues and } \\
\text { exhibits insulin-sensitizing, anti-inflammatory, and } \\
\text { anti-atherogenic properties. It is an independent } \\
\text { predictor of diabetes }\end{array}$
\end{tabular}

7. FetA

8. $\alpha-H B$

\section{L-GPC}

I0. Lp(a)

I I. Triglycerides

I2. HDL

A major lipoprotein

\section{I3. Ceramide Lipid molecules}

14. Ferritin and Ferritin is an intracellular protein that stores and transferrin
I5. MBL
-associated
serine
proteases
enzymes for innate immune responses
and activation of the lectin pathway of the complement system ${ }^{108}$

\section{Association with dysglycemia and complications}

Lower levels of adiponectin are associated with increased IR and obesity, while higher levels have been related to lifestyle intervention groups in diabetes prevention trials ${ }^{68}$

Adiponectin levels are inversely related to the risk of incident prediabetes, independent of ethnic or sex differences ${ }^{69}$

Adiponectin levels were directly correlated with insulin sensitivity and indirectly correlated with insulin secretion ${ }^{69}$

FetA correlates with increased risk of developing T2DM and associated complications $^{70}$

$\mathrm{IR}$, increased oxidative stress, and lipid oxidation may cause chronic shifts in glutathione synthesis leading to elevated $\alpha-\mathrm{HB}$ levels ${ }^{88}$

$\alpha-H B$ was found to be significantly associated with IR independent of sex, age, BMI, and collection site ${ }^{76}$

IR was associated with reductions in glycine and serine, which are upstream of $\alpha-K B$

L-GPC is a negative predictor of T2DM progression ${ }^{76,93}$

Lp(a) has an inverse relationship with prevalence of prediabetes and T2DM $^{95}$

Associated with $\beta$-cell dysfunction and reduced insulin secretion in subjects with prediabetes ${ }^{94,96}$

HDL-C promotes insulin secretion

- Low HDL-C concentration may lead to progression from prediabetes to diabetes

- Increased proportion of small HDL3 over HDL-C in subjects with prediabetes

- Decreased proportion of HDL-LpPLA ${ }_{2}$ in prediabetes ${ }^{97}$

Positively associated with prediabetes and T2DM ${ }^{85,98}$

Elevated serum ferritin and transferrin saturation have been strongly associated with increased risk of prediabetes and diabetes. Iron has properties that contribute to IR such as production of highly active radical formation, damage to DNA and cell membrane integrity, $\beta$-cell oxidative stress leading to decreased insulin secretory capacity, and interference with glucose uptake in skeletal muscles and adipocytes. Moreover, catalytic iron stimulates the formation of reactive oxidative species, hepatic dysfunction, and $\beta$-cell apoptosis, all of which contribute to IR $\mathrm{R}^{103-106}$ MASPI has been shown to positively correlate with prediabetes, diabetes, and CVD ${ }^{109}$

(Continued) 
Table I (Continued)

\section{Novel biomarkers}

Biomarker

|6. THBS |

\section{|7. GPLD |}

1 8. Acylcarnitine

19. MiRNA

\section{Mechanism of action}

THBSI directs formation of multiprotein complexes that modulate cellular phenotype (e.g., stimulates/inhibits migration of vascular smooth muscle cells or endothelial cells, respectively) ${ }^{110}$

GPLDI has a postulated role in the insulin-mimetic signaling pathway of glycosylphosphatidylinositol compounds, though the exact mechanism is not known

GPLDI cleavage generates second messengers that can act as inulin-mimetic molecules ${ }^{109}$

Acyl-carnitines interact with NF-K $\beta$, which promotes inflammation and IR

The precise role acyl-carnitines play has not yet been elucidated ${ }^{118}$

miRNAs are involved in cell growth, differentiation, proliferation, and death

Specific miRNAs ${ }^{124,126}$

miR- 192 regulates the tumor protein $\mathrm{p} 53$

miR-193b involved in brown adipocyte differentiation and inflammation reduction

miR-I5a thought to directly inhibit uncoupling protein-2 gene expression, leading to increased oxygen consumption and reduced ATP generation, thus promoting insulin synthesis

Others thought to play a role in $\beta$-cell function ${ }^{100}$
Association with dysglycemia and complications

THBSI positively associated with:109

- Higher prediabetes prevalence

- Increased IR

- Increased 2-hour glucose

- Adipose inflammation and metabolic dysregulation in obesity and type 2 diabetes

GPLDI positively associated with:109

- Type 2 diabetes and prediabetes (less strongly)

- MASPI, another novel prediabetes biomarker

- HDLs in serum

Elevated levels of acyl-carnitine found in individuals with prediabetes Associated with inflammation and IR 116,117

Many miRNAs have been found to be elevated in individuals with prediabetes $^{122}$

miR-I92 and 193b associated with subjects with IFG and IGT; associated with high triglyceride levels and fatty liver index ${ }^{120}$

Other miRNAs play a role in insulin production, secretion, and regulation $^{126}$

\section{Inflammatory biomarkers}

Biomarker Mechanism of action

\section{Association with dysglycemia and complications}

20. CRP Derived from IL-6-dependent hepatic

biosynthesis

Primary marker of acute phase response $\mathrm{e}^{|3|}$

2I. IL-6

IL-6 cytokines exhibit immunoregulatory actions and are involved in glucose homeostasis and metabolism through action on pancreatic $\beta$ cells, ${ }^{157}$ adipocytes, hepatocytes, and skeletal muscles ${ }^{158}$

22. WBCs
Associated with type 2 diabetes and IR

Found to be associated with prediabetes

CRP found more elevated in subjects who had prediabetes and IR than those with prediabetes but insulin sensitive ${ }^{108}$

Associated with type 2 diabetes and IR ${ }^{13 \mid}$
WBC count has been predictive of:

- Worsening insulin action

- Secretory function and T2DM

- Coronary heart disease

- Higher I-hour post-load glucose level ${ }^{140}$ 
Table I (Continued)

\begin{tabular}{|c|c|c|}
\hline \multicolumn{3}{|c|}{ Inflammatory biomarkers } \\
\hline Biomarker & Mechanism of action & Association with dysglycemia and complications \\
\hline 23. Fibrinogen & $\begin{array}{l}\text { Fibrinogen actions affect blood viscosity, platelet } \\
\text { aggregation, and fibrin formation }\end{array}$ & $\begin{array}{l}\text { Fibrinogen associated with: } \\
\text { - Prediabetes and weakly associated with diabetes } \\
\text { - Higher I-hour post-load glucose level atherosclerosis }{ }^{134}\end{array}$ \\
\hline 24. PAI-I & $\begin{array}{l}\text { Marker of reduced fibrinolysis } \\
\text { Decreased activity leads to defective } \\
\text { coagulation }^{147,148}\end{array}$ & Independent predictor of diabetes ${ }^{147}$ \\
\hline 25. IL- I 8 & IL- 18 increases during hyperglycemia ${ }^{149}$ & $\begin{array}{l}\text { Associated with increased risk of T2DM } \\
\text { Increased IL- I } 8 \text { correlated with progression from prediabetes to diabetes }{ }^{149}\end{array}$ \\
\hline 26. IL-I RA & $\begin{array}{l}\text { IL-IRA is an anti-inflammatory marker elevated } \\
\text { when IL-I pathway induced by glucose and free } \\
\text { fatty acids during overfeeding }{ }^{150}\end{array}$ & $\begin{array}{l}\text { Associated with: } \\
\text { - Decreasing insulin sensitivity } \\
\text { - Temporary increasing } \beta \text {-cell function } \\
\text { - Elevated in prediabetes and diabetes }{ }^{151}\end{array}$ \\
\hline
\end{tabular}

Abbreviations: HbA Ic, hemoglobin A I c; FPG, fasting plasma glucose; BMI, body mass index; FA, fructosamine; GA, glycated albumin; OGTT, oral glucose tolerance test; IR, insulin resistance; I, 5 AG, I, 5 anhydroglucitol; FetA, fetuin-A;TLR4, toll-like receptor 4;T2DM, type 2 diabetes mellitus; $\alpha$-HB, alpha-hydroxybutyrate; $\alpha$-KB, $\alpha$-ketobutyrate; L-GPC, L-alpha glycerylphosphorylcholine; Lp(a), lipoprotein(a); HDL-C, high-density lipoprotein cholesterol; HDL-LpPLA, HDL-associated lipoprotein-associated phospholipase A2; MBL, mannose binding lectin; CVD, cardiovascular disease; THBSI, thrombospondin I; GPLDI, glycosylphosphatidylinositol-specific phospholipase DI; NF-K $\beta$, nuclear factor-КB; miRNA, microRNA; IFG, impaired fasting glucose; IGT, impaired glucose tolerance; CRP, C-reactive protein; IL, interleukin; WBC, white blood cell; NLR, neutrophillymphocyte ratio; PAI-I, plasminogen activator inhibitor-I; IL-IRA, IL-I receptor antagonist; SGLT, sodium-glucose co-transporter 2.

this reason, HbA1c and OGTT levels may be discrepant as individuals classified as having prediabetes according to OGTT results may be normoglycemic by HbA1c standards.

Moreover, it is not clear which cut points for HbA1c would be most sensitive. Utilizing ADA criteria, HbA1c may miss individuals with prediabetes despite levels $<5.5 \%$ (37 mmol/ mol). ${ }^{26}$ The NHANES and Screening for Impaired Glucose Tolerance studies demonstrated that only $60-70 \%$ of subjects had normal glucose tolerance (NGT) when HbAlc levels were $<5.7 \%$ (39 mmol $/ \mathrm{mol}) .{ }^{27-29} \mathrm{In}$ addition, the HbAlc threshold for prediabetes does not consider ethnicity, body mass index (BMI), and age, all of which may significantly alter HbAlc levels. ${ }^{30-33}$ For example, HbAlc levels are higher among African Americans, Hispanics, and Asian/Pacific Islanders compared to non-Hispanic whites. One study demonstrated that $\mathrm{HbA} 1 \mathrm{c}$ is $0.3 \%$ higher in black men and $0.4 \%$ higher in black women. ${ }^{34}$ As a result, standard classification ranges may misdiagnose some individuals from certain ethnic groups with prediabetes, thus overestimating the prevalence of prediabetes.

$\mathrm{HbA} 1 \mathrm{c}$ is not always a reliable measurement of average circulating glucose levels. HbA1c has a life span related to the half-life of the red blood cell ranging from 90 to 120 days. ${ }^{35}$ Therefore, changes in the production rate or circulating life span of red blood cells will affect $\mathrm{HbA} 1 \mathrm{c}$ levels; for example, reduced production leads to a greater percent of older cells, whereas more rapid turnover reduces the average time during which the red cells are exposed to hyperglycemia. ${ }^{36}$ Several clinical conditions may result in overestimation or underestimation of HbAlc levels. Conditions in which $\mathrm{HbA} 1 \mathrm{c}$ is falsely elevated include iron deficiency anemia, asplenia, folate and vitamin B-12 deficiency, severe hypertriglyceridemia, and uremia. ${ }^{36}$ Falsely low HbA1c occurs in hemolytic anemia, blood loss, ${ }^{37,38}$ splenomegaly, and endstage renal disease. ${ }^{36}$ Hemoglobin variants, such as $\mathrm{HbS}$, $\mathrm{HbC}, \mathrm{HbD}$, and $\mathrm{HbE},{ }^{39}$ may also result in overestimation or under-estimation of $\mathrm{HbA} 1 \mathrm{c}$, depending on which method is used. ${ }^{36}$ For these reasons, HbAlc alone can be inadequate for diagnosing prediabetes, and more accurate diagnosis may require confirmation with other biomarkers. ${ }^{40}$

\section{Fructosamine}

Fructosamine (FA) has been used as an alternate glycemic marker for diabetes screening and may be potentially useful for diagnosing prediabetes. FA is a ketoamine created by glycosylation of total serum proteins, primarily albumin. ${ }^{41}$ FA increases in states of high glucose concentrations. Since it reflects average blood glucose concentrations over the previous $1-4$ weeks, ${ }^{38}$ it can be a useful clinical marker of short-term glycemic fluctuation and glucose control. ${ }^{38,52} \mathrm{FA}$ is especially useful in conditions that affect hemoglobin reliability, as already described, and has moderate sensitivity and high specificity (Table 1). ${ }^{52}$ Other advantages of FA include cost-effectiveness and convenience, as its measurement does not require fasting. ${ }^{42,43}$

Limitations of FA include higher within-subject variability and falsely low levels when conditions leading to rapid 
albumin turnover are present such as nephrotic syndrome and liver disease. ${ }^{44}$ There are conflicting data regarding its efficacy as a biomarker for prediabetes. Several studies found that FA correlates with hyperglycemia and HbA1c levels in both type 1 diabetes mellitus and type 2 diabetes mellitus (T2DM). ${ }^{41,45,46}$ FA may also indicate the risk for developing microvascular complications. ${ }^{45}$ However, not all studies have found that mean serum FA levels are useful for prediabetes screening. ${ }^{37,38,41,47-49}$

Thus, FA could be a valuable complementary marker in clinical conditions where HbA1c may be inaccurate. However, as the literature concerning FA is limited, and studies included small or niche patient cohorts, there are insufficient data to conclude its role as an alternate biomarker for microvascular complications.

\section{Glycated albumin}

Similar to FA, glycated albumin (GA) has been found to be a superior index of glycemic control than $\mathrm{HbA} 1 \mathrm{c}$ in patients with renal failure, hemolytic anemia, and those receiving blood transfusions. ${ }^{41,45}$ FA refers to all glycated serum proteins, which includes GA. Therefore, as FA is not corrected for albumin or total protein concentration, FA levels can fluctuate in certain conditions such as liver disease. Alternatively, GA measures the ratio of GA to total albumin. ${ }^{50}$ Thus, GA is preferred to FA in clinical conditions that result in protein loss such as nephrotic syndrome, liver, and thyroid disease.$^{50}$ While it is unclear whether FA should be corrected for total serum protein concentration, one study described an improvement in the correlation of FA with $\mathrm{HbA1c}$ when serum FA was corrected for albumin. ${ }^{46,51}$

Serum GA levels of $15-16 \%$ in Asian populations were associated with diabetes. ${ }^{52,53}$ Furthermore, GA has moderate sensitivity and specificity for diagnosing prediabetes and diabetes (Table 1). However, combining FPG $<100 \mathrm{mg} / \mathrm{dL}$ ( $5.56 \mathrm{mmol} / \mathrm{L})$ with serum $\mathrm{GA}<15 \%$ to exclude diabetes, and $\mathrm{FPG} \geq 126 \mathrm{mg} / \mathrm{dL}(7.0 \mathrm{mmol} / \mathrm{L})$ or serum $\mathrm{GA} \geq 17 \%$ to diagnose diabetes, increased the sensitivity of GA. There are no clear threshold values for FA and GA for prediabetes but one study used a level $\geq 230 \mu \mathrm{mol} / \mathrm{L}$ for FA and $\geq 13.35 \%$ for GA, both of which correlated with HbA1c of 5.7\% (39 $\mathrm{mmol} / \mathrm{mol}$ ) for detecting prediabetes. ${ }^{49} \mathrm{GA}$ as well as FA is associated with CVD, ischemic stroke, retinopathy, chronic kidney disease, and death in the Atherosclerosis Risk in Communities Study. ${ }^{51,54}$ These associations were similar to those of $\mathrm{HbA} 1 \mathrm{c},{ }^{54}$ suggesting that FA and GA may be useful alternative biomarkers in clinical conditions where $\mathrm{HbA} 1 \mathrm{c}$ is inaccurate ${ }^{51}$ The combination of GA with $\mathrm{HbA} 1 \mathrm{c}$ was shown to predict prediabetes with greater sensitivity than $\mathrm{HbA} 1 \mathrm{c}$ alone. ${ }^{49}$ In addition, GA may be superior to FA for detecting prediabetes, whereas the combination of FA with $\mathrm{HbA} 1 \mathrm{c}$ was not superior to $\mathrm{HbA} 1 \mathrm{c}$ alone. ${ }^{47,49,50,55}$

There are conditions in which GA may be inaccurate due to changes in albumin turnover. For example, the lower GA levels observed in obesity may be due to increased albumin catabolism and decreased rate of albumin synthesis from obesity-associated inflammation. However, the precise mechanism for the lower GA in obesity is unclear. ${ }^{52,53,56-58}$ GA may be artificially low in individuals with increased BMI, body fat mass, and visceral adiposity. ${ }^{53}$ The mechanism for alterations in GA levels in these conditions is not well understood. ${ }^{59}$

\section{I,5 Anhydroglucitol}

1,5 Anhydroglucitol (1,5 AG), a dietary monosaccharide, has been suggested as a prediabetes marker. As the proximal tubules in the kidney have a greater affinity for glucose than 1,5 AG, high glucose levels prevent 1,5 AG reabsorption resulting in elevated 1,5 AG urinary excretion. Therefore, plasma 1,5 AG concentrations are inversely correlated with plasma glucose levels ${ }^{60}$ demonstrated in a study in which the 1,5 AG level was highest in the control group followed by the prediabetes and diabetes groups, respectively. ${ }^{60}$ Some studies, but not all, have found an inverse relationship between 1,5 AG and OGTT 2-hour post-glucose levels. ${ }^{61,62}$ Studies have also shown an inverse relationship between 1,5 AG and $\mathrm{HbA} 1 \mathrm{c}$ as well as FPG levels. ${ }^{63}$

Similar to FA, 1,5 AG may be a useful biomarker as it reflects glucose levels within the preceding 10-14 days. ${ }^{61} 1,5$ AG is stable, reproducible, and less costly when compared to other glycemic diagnostic tests. ${ }^{61}$ It may be useful for identifying postprandial glycemic excursions and individuals at risk of complications as 1,5 AG has been associated with retinopathy and microvascular and macrovascular events in diabetes. However, it is unclear if 1,5 AG is superior to HbA1c. Plasma 1,5 AG levels can change based on diet, sex, ${ }^{64,65}$ and race. Levels are also affected by renal hemodynamics or treatment with sodium-glucose co-transporter 2 inhibitors. ${ }^{66,67}$ There is no consensus on the use of $1,5 \mathrm{AG}$ as a prediabetes screening tool. ${ }^{65,66}$

\section{Adiponectin}

Adiponectin, derived from adipose tissue, exhibits insulinsensitizing, anti-inflammatory, and anti-atherogenic properties and is an independent predictor of diabetes. ${ }^{68}$ Lower levels of adiponectin are associated with increased IR and 
obesity, while higher levels have been related to lifestyle intervention groups in diabetes prevention trials. ${ }^{68}$ The association of adiponectin with diabetes risk appears to be evident at a much earlier stage in the progression to diabetes; more specifically, lower adiponectin levels were observed a decade before diabetes was diagnosed, particularly in men. ${ }^{68}$ Additionally, in offspring of parents with T2DM, baseline adiponectin levels are inversely related to the risk of incident prediabetes independent of ethnic or sex differences. ${ }^{69}$ Using the hyperinsulinemic euglycemic clamp and intravenous glucose tolerance test, adiponectin levels were directly correlated with insulin sensitivity and indirectly with insulin secretion. ${ }^{69}$

\section{Fetuin-A}

Fetuin-A (FetA) is a hepatic secretory glycoprotein that correlates with increased risk of developing T2DM and associated complications. ${ }^{70}$ Importantly, unlike adiponectin, the EPIC-Potsdam prospective cohort study found that FetA was independently associated with T2DM after controlling for BMI and waist circumference. ${ }^{70}$ FetA has been proposed to promote lipid-induced IR through the toll-like receptor 4 (TLR4)-inflammatory signaling pathway, which results in production of inflammatory cytokines. ${ }^{71}$ As chronic inflammation induced by free fatty acids (FFAs) has been thought to result in IR, the FFA-TLR4 signaling pathway has been recognized as a cause of IR. However, FFA may not bind directly to TLR4. Pal et al showed that FetA binds to TLR4, and regulates insulin sensitivity through this interaction. ${ }^{71}$ High-fat diet-fed FetA knockdown mice have less TLR4mediated inflammatory signaling in adipose tissue and IR, whereas intravenous injection of FetA in this model induced inflammatory signaling and IR. FFA-induced inflammatory cytokine expression in adipocytes occurred only in the presence of both FetA and TLR4; removing either prevented FFA-induced IR. FFAs did not produce IR in adipocytes with mutated TLR4 or galactoside-cleaved FetA. FetA, TLR4, interleukin (IL)-6, and tumor necrosis factor (TNF)- $\alpha$ were elevated in obese subjects with diabetes, suggesting an association between lipids, FetA concentrations, and TLR4 expression with IR.

Studies of the association between FetA concentration and CVD have been conflicting. No association, ${ }^{72}$ a positive association, ${ }^{73}$ or an inverse association have been reported. However one multi-ethnic US study found a positive trend in those with IFG or diabetes. ${ }^{74}$ FetA may be associated with higher risk of CVD in those susceptible to the development of IR. ${ }^{74}$
Taken together, these findings suggest that FetA is an endogenous ligand for TLR4 through which lipids induce IR. FetA may therefore serve as a novel therapeutic target for IR.

\section{Metabolites and microRNA Amino acids}

Felig et al found that fasting branched chain and aromatic amino acids correlated with obesity and serum insulin, whereas glucose loading decreased amino acid levels in insulin-sensitive individuals but not in insulin-resistant individuals. ${ }^{75}$ This is likely due to insulin-mediated inhibition of proteolysis by skeletal muscle. More recent studies have demonstrated a correlation between amino acids and prediabetes, IR, and obesity. ${ }^{76}$ Branched chain amino acids (BCAAs), isoleucine, leucine, valine, tyrosine, as well as aromatic amino acid phenylalanine and glycine have been significantly associated with diabetes risk..$^{75,77-80}$ In addition, glutamine, methionine, cysteine, and 2-aminoadipic acid are increased in insulin-resistant states. ${ }^{81-83}$ By contrast, glycine levels are decreased in individuals with prediabetes. ${ }^{84-86}$ To further support this, a comprehensive systematic review and meta-analysis demonstrated positive associations with BCAAs and aromatic amino acids and inverse associations with glycine and glutamine with risk of T2DM. ${ }^{85}$ Alterations in circulating amino acid levels may represent a significant predictive biomarker for IR and T2DM.

\section{$\alpha$-Hydroxybutyrate}

$\alpha$-Hydroxybutyrate $(\alpha-\mathrm{HB})$ is an organic acid byproduct produced during the synthesis of $\alpha$-ketobutyrate $(\alpha-K B)$, a product of amino acid catabolism (threonine and methionine) and glutathione anabolism (cysteine formation pathway) in hepatic tissue. ${ }^{76}$ The formation of $\alpha-\mathrm{KB}$ is catalyzed by lactate dehydrogenase and $\alpha$-HB. During oxidative stress, the rate of hepatic glutathione synthesis increases, resulting in increased production of $\alpha-K B .{ }^{85,87}$ This causes a decrease in the availability of L-cysteine for glutathione synthesis and an elevation in $\alpha$-HB. Thus, in IR, increased oxidative stress and lipid oxidation may cause chronic shifts in glutathione synthesis leading to elevated $\alpha$-HB levels. ${ }^{88,89}$ This is demonstrated by increased urinary $\alpha$-HB excretion in IR..$^{90}$

Using $\alpha-\mathrm{HB}$ as a biomarker, previous studies were able to distinguish NGT-insulin-sensitive (NGT-IS) subjects from IGT and IFG subjects and NGT-IS subjects from those with NGT-IR. Furthermore, using multiple logistic regression analyses, $\alpha$-HB was found to be significantly associated with IR, independent of sex, age, BMI, and collection site. ${ }^{76}$ Furthermore, IR was associated with reductions in glycine 
and serine, which are upstream of $\alpha-\mathrm{KB}$, and an elevation in cysteine. The underlying mechanism may be related to redox imbalance with IR resulting in an increase in $\alpha$-HB. $\alpha$-HB may be an effective biomarker for prediabetes. ${ }^{76,89}$

\section{Linoleoyl-glycerophosphocholine}

Choline-containing phospholipids and sphingomyelins have been associated with increased risk of T2DM. Linoleoylglycerophosphocholine (L-GPC) was investigated in the Relationship Between Insulin Sensitivity and Cardiovascular Disease study. ${ }^{91}$ L-GPC is formed by hepatic phospholipase A2 and circulatory lecithin-cholesterol acyltransferase. Phospholipase A2 activity is increased with inflammation. L-GPC may inhibit phospholipase A2 through noncompetitive enzyme inhibition, thereby exhibiting anti-inflammatory properties. $^{76,92}$ Thus, L-GPC is a negative predictor of T2DM progression in contrast to $\alpha-\mathrm{HB}$, a positive predictor. ${ }^{76,93}$

\section{Lipoprotein(a)}

Lipoprotein(a) $[\mathrm{Lp}(\mathrm{a})]$ is synthesized by the liver. Elevated levels of LP(a) are an independent risk factor for developing CVD. ${ }^{94}$ An inverse relationship between serum Lp(a) and the prevalence of prediabetes and T2DM has been reported, although the mechanism for the relationship between serum Lp(a) and T2DM is not clear. ${ }^{95}$ Insulin may play a role in reducing $\mathrm{Lp}(\mathrm{a})$ levels. $^{95}$

\section{Triglycerides and high-density lipoprotein}

Elevated serum triglyceride ( $\mathrm{Tg}$ ) levels have been associated with $\beta$-cell dysfunction and reduced insulin secretion in prediabetes. ${ }^{94}$ Mechanistically, hypertriglyceridemia reduces glucose-induced insulin secretion through the glucose-fatty acid cycle, and promotes $\beta$-cell apoptosis by stimulating the production of ceramide and nitric oxide. ${ }^{96}$ Also, elevated $\mathrm{Tg}$ levels can cause lipotoxicity by accumulating within pancreatic $\beta$ cells. ${ }^{94,96}$

Cholesteryl ester transfer protein mediates the exchange of lipids from Tg-rich lipoproteins with high-density lipoprotein (HDL). Increased Tg levels in insulin-resistant states accelerate this exchange. ${ }^{97}$ Then, the Tg in HDL cholesterol (HDL-C) are hydrolyzed by hepatic lipase, resulting in smaller HDL-C particles. ATP-binding cassette transporter A (ABCA1) mediates the efflux of cholesterol to small HDL3 particles. ${ }^{97}$ Subjects with prediabetes have significantly increased levels of small HDL3 particles compared with HDL-C levels. ${ }^{97}$ The proportion of small HDL3 particles is positively associated with $\mathrm{Tg}$ and negatively associated with HDL-C. ${ }^{97}$ In contrast to Tg, HDL-C promotes insulin secretion through its interaction with ABCA1. Low HDL-C concentrations may also lead to progression to diabetes from prediabetes. However, it is unclear if HDL-C levels are associated with $\beta$-cell dysfunction. ${ }^{96}$

Lipoprotein-associated phospholipase $\mathrm{A}_{2}\left(\mathrm{LpPLA}_{2}\right)$ is an enzyme that degrades oxidatively fragmented phospholipids and may play a role in atherogenesis. ${ }^{97}$ Individuals with IFG have significantly decreased HDL-associated LpPLA 2 (HDL$\mathrm{LpPLA}_{2}$ ) activity compared with subjects with normoglycemia. Low-density lipoprotein-associated LpPLA 2 may exert pro-inflammatory effects, whereas HDL-LpPLA 2 may have an atheroprotective role. ${ }^{97}$ Increased levels of small HDL3 particles and decreased activity of the anti-atherogenic HDLLpPLA $_{2}$ were found in subjects with IFG. ${ }^{97}$ Thus, subclasses of HDL-C may play a role in the pathogenesis of prediabetes.

\section{Ceramide}

In addition to $\mathrm{Tg}$, ceramides have a positive association with prediabetes and T2DM. ${ }^{85,98}$ Ceramides are lipid molecules that mediate IR. ${ }^{99,100}$ Studies have shown that ceramides inhibit insulin action by decreasing phosphorylation and activation of Akt; accumulate in insulin-resistant tissues; and induce inflammation through the nuclear factor- $\kappa \mathrm{B}(\mathrm{NF}-\mathrm{K} \beta)$ TNF- $\alpha$ axis. ${ }^{100,101}$ Furthermore, ceramides correlate with coronary artery disease. ${ }^{102}$

Additional studies are needed to understand the relationships between lipid metabolism, prediabetes, and diabetes.

\section{Ferritin and transferrin}

Ferritin is an intracellular protein that stores and releases iron. Elevated serum ferritin and transferrin saturation have been strongly associated with increased risk of prediabetes and diabetes. ${ }^{103,104}$ Furthermore, a positive correlation with increased FPG and serum ferritin has been demonstrated. ${ }^{104}$ Iron contributes to IR through the production of highly active radical formation, damage to DNA and cell membrane integrity, $\beta$-cell oxidative stress resulting in decreased insulin secretory capacity, ${ }^{105}$ and interference with glucose uptake in skeletal muscles and adipocytes. Moreover, catalytic iron stimulates the formation of reactive oxidative species, hepatic dysfunction, and $\beta$-cell apoptosis, ${ }^{105,106}$ all of which contribute to IR. Dietary iron restriction or chelation prevents the development of diabetes and loss of $\beta$-cell function. ${ }^{105}$ The threshold levels of ferritin that correlate with IR are uncertain as these may vary with sex and age. ${ }^{107}$ Additional studies are needed to better understand ferritin and its role in prediabetes. 


\section{Mannose binding lectin serine peptidase, thrombospondin I, and glycosylphosphatidylinositol-specific phospholipase DI}

Mannose binding lectin-associated serine proteases are important for innate immune responses and activation of the lectin pathway of the complement system. ${ }^{108}$ MASP1, the most abundant serine protease of the complement lectin pathway, has a major role in the complement cascade. ${ }^{108}$ MASP1 has been shown to positively correlate with prediabetes, diabetes, as well as CVD. One study demonstrated that the onset of prediabetes and IR occurred earlier in those with increased MASP1 plasma levels. ${ }^{109}$ There was a positive association with elevated FPG and 2-hour glucose levels, but this weakened when adjusted for triacylglycerol levels. This suggests that triacylglycerol may mediate part of the association between MASP1 and HOMA-IR. ${ }^{109}$

Thrombospondin 1 (THBS1) and glycosylphosphatidylinositol-specific phospholipase D1 (GPLD1) are positively associated with prediabetes, whereas apolipoprotein A-IV (ApoA-IV) is inversely associated. ${ }^{109}$ THBS1 is a glycoprotein and member of the THB family, which has numerous functions such as cellular adhesion and migration regulation, cytoskeletal organization, cell proliferation and apoptosis, and cell-to-cell interactions. ${ }^{110}$ This matrix protein has been found to be associated with increased IR, which may be attributable to THB's inflammatory properties, as well as increased 2-hour glucose levels and higher prediabetes prevalence. ${ }^{109}$

GPLD1, mainly produced in the liver, releases glycosylphosphatidylinositol-anchored membrane proteins. ${ }^{111}$ It is associated with serum lipoproteins and has been linked with diabetes and prediabetes. ${ }^{109,111}$ ApoA-IV, a component of chylomicrons, very low-density lipoprotein and HDL, has been shown to have a significant inverse relationship with prediabetes and diabetes. ${ }^{109}$ The exact role of ApoAIV in vivo is unknown aside from regulating appetite and chylomicron production but it may have antioxidant and anti-inflammatory properties. ${ }^{112,113}$

There are limited studies describing the relationship between THBS1, GPLD1, and ApoA-IV and prediabetes; therefore, more data are required to better understand their respective roles.

\section{Acyl-carnitine}

Fatty acid oxidation (FAO) is a major source of cellular energy. ${ }^{114}$ L-carnitine plays a significant role in FAO as it transports activated long chain fatty acids (LCFA) from the cytosol into the mitochondria, a process referred to as the carnitine shuttle. Once inside, fatty acids undergo esterification to CoA. Carnitine palmitoyltransferase 1 exchanges the CoA moiety for carnitine resulting in acyl-carnitine production. ${ }^{115}$ Recently, serum levels of acyl-carnitines have been shown to be elevated in prediabetes. ${ }^{16,117}$ However, the essential role of acyl-carnitine in FAO and its mechanism in IR are uncertain. It has been proposed that impairment of FAO and dysregulated mitochondrial function result in accumulation of intermediary products such as acyl-carnitines. Thus, there is a mismatch of LCFA delivery and the tricarboxylic acid cycle. ${ }^{118}$ Furthermore, acyl-carnitines interact with NF-K $\beta$, which promotes inflammation and IR. ${ }^{118}$ However, there are few studies of acyl-carnitines in prediabetes.

\section{MicroRNAs}

MicroRNAs (miRNAs) are small, noncoding RNAs involved in post-transcriptional gene expression. These are pertinent to many biological and pathophysiological processes such as growth, development, differentiation, proliferation, and cell death. Recently, miRNAs have been studied in prediabetes, ${ }^{119-121}$ several of which were increased including miR-192 and miR-193b. miR-192 regulates tumor protein $\mathrm{p} 53$, and miR-193b is important for the differentiation of brown adipocytes and inflammation reduction. ${ }^{122}$ Levels of both miRNAs were elevated in those with IFG and IGT. Furthermore, miR-192 and miR-193b have been correlated with Tg levels and the fatty liver index in animal models, ${ }^{120}$ which may be significant as a fatty liver can be associated with prediabetes. ${ }^{123}$ Moreover, exercise was shown to significantly decrease miR-192 and miR-193b concentrations. ${ }^{120}$

Other miRNAs significantly elevated in T2DM include miR-9, miR-29a, miR-30d, miR-34a, miR-124a2, miR-146a, and miR-375, all thought to play a role in $\beta$-cell function. These miRNAs were found to negatively regulate insulin expression, production, or secretion. However, no statistically significant increases were found in subjects with prediabetes, suggesting that there may be reversible pathophysiological processes that occur during prediabetes but not in T2DM. ${ }^{124}$

Additional miRNAs are decreased in prediabetes. Circulating levels of miR-126, abundant in endothelial cells playing a role in endothelial homeostasis and vascular integrity, are decreased in IGT/IFG and T2DM. ${ }^{125}$ miR-126 levels are increased with diet and exercise. miRNA-15a levels were also significantly lower in prediabetes, T2DM, and IFG/ IGT. ${ }^{119}$ miR-15a is thought to regulate and promote insulin biosynthesis by inhibiting endogenous uncoupling protein-2 
gene expression and increasing insulin secretion. ${ }^{126}$ Therefore, miR-15a has been suggested to play a significant role in $\beta$-cell function and insulin synthesis.

\section{Inflammatory markers}

Prediabetes and IR are characterized by a marked inflammatory state. ${ }^{127-129}$ Biochemical markers of acute-phase reactants and inflammatory cytokines are elevated on the onset of T2DM and may even further increase with disease progression. These markers, such as C-reactive protein (CRP), white blood cell count, and fibrinogen, have been investigated as potential predictors for the development of T2DM such as in the Atherosclerosis Risk in Communities study. ${ }^{130}$

\section{CRP and IL-6}

CRP is the most widely studied inflammatory marker in CVD and its clinical use continues to evolve. CRP is primarily derived from IL-6-dependent hepatic biosynthesis and is a primary marker of the acute phase response. Many investigations have demonstrated elevated levels of both IL-6 and CRP among individuals with T2DM and IR. In the Women's Health Study, a nationwide cohort of 27,628 women without diabetes mellitus (DM), CVD, or cancer at baseline, 188 women developed DM over a 4-year follow-up period. ${ }^{131}$ Median baseline levels of IL-6 and CRP were significantly higher among cases than controls. In addition, higher levels of IL-6 and CRP were associated with a greater risk of diabetes development. Relative risks of incident T2DM for increasing quartiles of IL-6 were 1.0, 2.5, 4.1, and 7.5, respectively ( $p<0.001$ for trend), and for increasing quartiles of CRP were 1.0, 2.2, 8.7, and 15.7, respectively ( $p<0.001$ for trend). While adjustment for BMI attenuated these relative risks, the results were still positive. These findings were similar when only including women with a baseline HbA1c of $6.0 \%$ (42 $\mathrm{mmol} / \mathrm{mol}$ ) or less and after adjustment for fasting insulin levels. This suggests that these inflammatory markers may be useful in identifying individuals at risk of developing T2DM.

The Insulin Resistance Atherosclerosis Study (IRAS) was a multicenter study of 1,625 individuals followed over 5.2 years. ${ }^{132}$ Individuals with prediabetes were defined as those developing diabetes during follow-up. Subjects with prediabetes who were also insulin resistant had elevated CRP levels compared to both insulin-sensitive individuals with prediabetes and non-diabetics. These differences were thought partly due to differences in body weight. Since subjects with prediabetes and IR were not hyperglycemic, subclinical inflammation could not be attributed solely to hyperglycemia. This hypothesis was supported in another study demonstrating that the glycemic index was not associated with CRP and risk of T2DM, suggesting that hyperglycemia per se is not the underlying mechanism linking diabetes and inflammation. ${ }^{133}$

The association between CRP and prediabetes has been confirmed in other studies. The Gutenberg Health Study was a prospective, observational single-center cohort study that included 15,010 adults, 1,425 of whom had prediabetes and 1,299 had diabetes according to HbA1c concentrations. ${ }^{134}$ CRP was shown to increase incrementally from normoglycemia to prediabetes ( $1.4 \mathrm{vs} .2 .3 \mathrm{mg} / \mathrm{L}$ ), whereas only a small increase was observed between subjects with prediabetes and diabetes ( 2.3 vs. $2.4 \mathrm{mg} / \mathrm{L}$ ), suggesting that early immune activation plays a role in the onset of diabetes. Genetic variants in the innate immune system and inflammatory cascade also affect CRP and predisposition to T2DM. ${ }^{128,135}$

Other studies have further supported the association between increased levels of CRP and IL- 6 and prediabetes. ${ }^{127,136}$ In a meta-analysis evaluating IL-6 with the risk for developing T2DM, the overall relative risk was $1.31(95 \%$ confidence interval [CI] 1.17-1.46; $p=0.000)$ per $1 \log \mathrm{pg} / \mathrm{mL}$ increment in IL-6 levels. ${ }^{137}$ In another meta-analysis, these authors found that the overall risk of T2DM was 1.26 (95\% CI $1.16-1.37 ; p=0.000)$ per $1 \log \mathrm{mg} / \mathrm{L}$ increment in CRP levels. ${ }^{137}$ There may be differences in CRP as a predictor of diabetes in women compared to men. ${ }^{137}$ Interestingly, the meta-analysis showed that IL-6 was more strongly associated with T2DM than CRP, questioning the pathogenesis of subclinical inflammation in diabetes. CRP may therefore have a potential downstream role in this process but may not be the precipitating factor. However, in contrast to the latter findings, another study demonstrated that CRP was elevated in obesity and IR, whereas levels were low in insulin-sensitive or obese individuals. ${ }^{138}$

\section{White blood cell count, fibrinogen, and hematological indices}

White blood cell count and fibrinogen are also markers of immunity and inflammation that may have clinical relevance for disease progression and organ-specific complications in diabetes. Leukocytosis may also predict coronary heart disease. ${ }^{139}$ Therefore, the early identification of high-risk individuals may prevent the onset and/or progression of CVD. A high white blood cell count has been shown to predict worsening insulin action, insulin secretory function, and T2DM development in Pima Indians. ${ }^{140}$ Fibrinogen may contribute to atherosclerosis by affecting blood viscosity, platelet aggregation, and fibrin formation. Fibrinogen also 
modulates coagulation activation and fibrinolysis, and may enhance plaque progression. In the Gutenberg Health Study, fibrinogen levels were higher in prediabetes than in diabetes, although the reason for this finding is not clear. ${ }^{134}$

The neutrophil-lymphocyte ratio (NLR) and plateletlymphocyte ratio (PLR) are also indicators of subclinical inflammation. In a study of 110 adults, subjects were divided into four groups: NGT, IGT, newly diagnosed T2DM, and known T2DM without complications. NLR values were significantly higher in those with prediabetes, newly diagnosed diabetes, and known diabetes compared to the control group. ${ }^{141}$ PLR values were significantly lower in the prediabetes and newly diagnosed diabetes groups but higher in subjects with T2DM. Of note, NLR was higher in obese patients with diabetes than in those without diabetes. NLR has also been associated with both microvascular and macrovascular complications in diabetes. ${ }^{141-144}$

Another investigation demonstrated that 1-hour post-load glucose levels were associated with a significantly higher white blood cell count and fibrinogen. ${ }^{145}$ Fiorentino et al showed that individuals with prediabetes had a significant increase in CRP, fibrinogen, and white blood cell count after adjusting for sex, age, smoking, and fasting and 1- and 2-hour post-load glucose levels. ${ }^{146}$

\section{Plasminogen activator inhibitor-I}

Tissue plasminogen activator-1 (PAI-1) is a marker of reduced fibrinolysis with decreased activity resulting in coagulation abnormalities. ${ }^{147}$ Changes in PAI-1 levels were shown to be an independent predictor of incident diabetes in IRAS. ${ }^{148}$

\section{IL-I8}

Through oxidative mechanisms, hyperglycemia acutely increases cytokine concentrations including plasma IL-6, as already described, as well as TNF- $\alpha$ and IL-18. ${ }^{149}$ In a prospective case-cohort study, subjects with IL-18 in the highest quartile had a $70 \%$ increased risk of developing T2DM compared to those in the lowest quartile. ${ }^{149} \mathrm{IL}-18$ also increased with progression from prediabetes to diabetes in the Gutenberg study. ${ }^{134}$

\section{IL-I receptor antagonist}

The IL-1 pathway may be induced by glucose and FFAs in the setting of overfeeding and contribute to an inflammatory state. ${ }^{150}$ The IL-1 receptor antagonist (IL-1RA), produced by adipocytes, is an anti-inflammatory marker elevated in prediabetes and diabetes, possibly as a reactive response to inflammation. ${ }^{134}$ In the Whitehall Study, a case-cohort study of 355 individuals with incident T2DM, an increase in IL1RA in individuals with prediabetes occurred in parallel with decreasing insulin sensitivity, transiently increasing $\beta$-cell function, and 2-hour glucose levels, all of which occurred years before the occurrence of T2DM. ${ }^{151}$ Levels of IL-1RA were elevated 13 years before the diagnosis of T2DM. Of note, IL-1RA increased rapidly 6 years before diagnosis even after adjusting for obesity.

\section{Patient-focused perspectives}

According to the Centers for Disease Control and Prevention, as many as $90 \%$ of individuals with prediabetes are undiagnosed $^{1}$ and therefore fail to receive guidance on lifestyle changes to prevent progression to T2DM. While HbA1c and glucose determinations for screening have been used in clinical practice for many years, each has deficiencies. As previously discussed, since $\mathrm{HbA} 1 \mathrm{c}$ is insensitive for diagnosing acute and intermittent hyperglycemia and can be affected by various medical conditions and ethnicity, identification of other biomarkers would be of immense value. OGTT, while providing important information with regard to risk of developing T2DM that HbA1c or FPG do not, is associated with considerable variability, requires fasting, and is invasive and time consuming. However, intermediate time points during the OGTT (e.g., 30 or 60 minute post-load values) appear to predict progression to T2DM better than fasting, 2-hour postload glucose or HbA1c levels, making this approach more favorable with the possibility of shortening the traditional 2-hour test. ${ }^{152}$ Additional studies are required to identify the most accurate biomarker(s), recognizing that a single determinant will likely have inherent limitations. Therefore, combining several biomarkers may more precisely predict those at high risk for developing prediabetes and subsequent progression to diabetes.

\section{Conclusion and future perspectives}

Categorical or absolute definitions of dysglycemia when applied to a continuous pathophysiologic process may inadvertently underestimate those at risk for progression. Progressively rising glucose levels, even within the so-called "normal range", occur relatively late in the evolution to T2DM when $\beta$-cell function may already be reduced. ${ }^{153}$ Therefore, a vital need exists to identify more sensitive and precise biomarkers capable of predicting progression to dysglycemic states at the earliest time point when $\beta$-cell function is still relatively more optimal and may be more responsive to lifestyle modification. Combining biomarkers in a clinical setting may provide better sensitivity and specificity in predicting prediabetes and 
diabetes. Additional comparison studies of biomarkers will be required to ascertain their clinical utility. Furthermore, genetic studies assessing mutations may provide additional insight into associations with metabolic abnormalities. ${ }^{153,154}$

\section{Disclosure}

The authors report no conflicts of interest in this work.

\section{References}

1. Centers for Disease Control. National Diabetes Statistics Report: Estimates of Diabetes and its Burden in the United States. Atlanta, GA: U.S. Department of Health and Human Services; 2014.

2. International Diabetes Federation. IDF Diabetes Atlas. 7th ed. Brussels, Belgium: International Diabetes Federation; 2015.

3. Bansal N. Prediabetes diagnosis and treatment: a review. World $J$ Diabetes. 2015;6(2):296-303.

4. Kahn SE. The relative contributions of insulin resistance and beta-cell dysfunction to the pathophysiology of Type 2 diabetes. Diabetologia. 2003;46(1):3-19.

5. Gong Q, Gregg EW, Wang J, et al. Long-term effects of a randomised trial of a 6-year lifestyle intervention in impaired glucose tolerance on diabetes-related microvascular complications: the China Da Qing Diabetes Prevention Outcome Study. Diabetologia. 2011;54(2):300-307.

6. Li G, Zhang P, Wang J, et al. Cardiovascular mortality, all-cause mortality, and diabetes incidence after lifestyle intervention for people with impaired glucose tolerance in the Da Qing Diabetes Prevention Study: a 23-year follow-up study. Lancet Diabetes Endocrinol. 2014;2(6):474-480.

7. Tuomilehto J, Lindström J, Eriksson JG, et al; Finnish Diabetes Prevention Study Group. Prevention of type 2 diabetes mellitus by changes in lifestyle among subjects with impaired glucose tolerance. $N$ Engl J Med. 2001;344(18):1343-1350.

8. Lindström J, Louheranta A, Mannelin M, et al; Finnish Diabetes Prevention Study Group. The Finnish Diabetes Prevention Study (DPS): lifestyle intervention and 3-year results on diet and physical activity. Diabetes Care. 2003;26(12):3230-3236.

9. Diabetes Prevention Program Research Group, Knowler WC, Fowler SE, Hamman RF, et al. 10-year follow-up of diabetes incidence and weight loss in the Diabetes Prevention Program Outcomes Study. Lancet. 2009;374(9702):1677-1686.

10. Sjöström CD, Lissner L, Wedel H, Sjöström L. Reduction in incidence of diabetes, hypertension and lipid disturbances after intentional weight loss induced by bariatric surgery: the SOS Intervention Study. Obes Res. 1999;7(5):477-484.

11. Abdul-Ghani MA, Tripathy D, DeFronzo RA. Contributions of beta-cell dysfunction and insulin resistance to the pathogenesis of impaired glucose tolerance and impaired fasting glucose. Diabetes Care. 2006;29(5):1130-1139.

12. Abdul-Ghani MA, Jenkinson CP, Richardson DK, Tripathy D, DeFronzo RA. Insulin secretion and action in subjects with impaired fasting glucose and impaired glucose tolerance: results from the Veterans Administration Genetic Epidemiology Study. Diabetes. 2006;55(5):1430-1435.

13. Festa A, D'Agostino R Jr, Hanley AJ, Karter AJ, Saad MF, Haffner SM. Differences in insulin resistance in nondiabetic subjects with isolated impaired glucose tolerance or isolated impaired fasting glucose. Diabetes. 2004;53(6):1549-1555.

14. American Diabetes Association. Standards of medical care in diabetes-2014. Diabetes Care. 2014;37(Suppl 1):S14-S80.

15. American Diabetes Association. (2). Classification and diagnosis of diabetes. Diabetes Care. 2015;38(Suppl 1):S8-S16.

16. World Health Organization. Definition and diagnosis of diabetes mellitus and intermediate hyperglycemia. 2006. Geneva: World Health Organization; 2013.
17. Bookchin RM, Gallop PM. Structure of hemoglobin AIc: nature of the N-terminal beta chain blocking group. Biochem Biophys Res Commun. 1968;32(1):86-93.

18. Pfister R, Sharp SJ, Luben R, Khaw KT, Wareham NJ. No evidence of an increased mortality risk associated with low levels of glycated haemoglobin in a non-diabetic UK population. Diabetologia. 2011;54(8):2025-2032.

19. White NH, Sun W, Cleary PA, et al; DCCT-EDIC Research Group. Effect of prior intensive therapy in type 1 diabetes on 10-year progression of retinopathy in the DCCT/EDIC: comparison of adults and adolescents. Diabetes. 2010;59(5):1244-1253.

20. Diabetes Control and Complications Trial Research Group, Nathan DM, Genuth S, Lachin J, et al. The effect of intensive treatment of diabetes on the development and progression of long-term complications in insulin-dependent diabetes mellitus. $N$ Engl $J$ Med. 1993;329(14):977-986.

21. Stratton IM, Adler AI, Neil HA, et al. Association of glycaemia with macrovascular and microvascular complications of type 2 diabetes (UKPDS 35): prospective observational study. $B M J$. 2000;321(7258):405-412.

22. Report of the expert committee on the diagnosis and classification of diabetes mellitus. Diabetes Care. 1997;20(7):1183-1197.

23. Bonora E, Tuomilehto J. The pros and cons of diagnosing diabetes with A1C. Diabetes Care. 2011;34(Suppl 2):S184-S190.

24. Olson DE, Rhee MK, Herrick K, Ziemer DC, Twombly JG, Phillips LS. Screening for diabetes and pre-diabetes with proposed A1C-based diagnostic criteria. Diabetes Care. 2010;33(10):2184-2189.

25. Lorenzo C, Wagenknecht LE, Hanley AJ, Rewers MJ, Karter AJ, Haffner SM. A1C between 5.7 and $6.4 \%$ as a marker for identifying pre-diabetes, insulin sensitivity and secretion, and cardiovascular risk factors: the Insulin Resistance Atherosclerosis Study (IRAS). Diabetes Care. 2010;33(9):2104-2109.

26. Zhou X, Pang Z, Gao W, et al. Performance of an A1C and fasting capillary blood glucose test for screening newly diagnosed diabetes and pre-diabetes defined by an oral glucose tolerance test in Qingdao, China. Diabetes Care. 2010;33(3):545-550.

27. James C, Bullard KM, Rolka DB, et al. Implications of alternative definitions of prediabetes for prevalence in U.S. adults. Diabetes Care. 2011;34(2):387-391.

28. Guo F, Moellering DR, Garvey WT. Use of HbA1c for diagnoses of diabetes and prediabetes: comparison with diagnoses based on fasting and 2-hr glucose values and effects of gender, race, and age. Metab Syndr Relat Disord. 2014;12(5):258-268.

29. Malkani S, Mordes JP. Implications of using hemoglobin A1C for diagnosing diabetes mellitus. Am J Med. 2011;124(5):395-401.

30. Christensen DL, Witte DR, Kaduka L, et al. Moving to an A1C-based diagnosis of diabetes has a different impact on prevalence in different ethnic groups. Diabetes Care. 2010;33(3):580-582.

31. Herman WH, Ma Y, Uwaifo G, et al; Diabetes Prevention Program Research Group. Differences in A1C by race and ethnicity among patients with impaired glucose tolerance in the Diabetes Prevention Program. Diabetes Care. 2007;30(10):2453-2457.

32. Li J, Ma H, Na L, et al. Increased hemoglobin A1c threshold for prediabetes remarkably improving the agreement between A1c and oral glucose tolerance test criteria in obese population. J Clin Endocrinol Metab. 2015;100(5):1997-2005.

33. Pani LN, Korenda L, Meigs JB, et al. Effect of aging on A1C levels in individuals without diabetes: evidence from the Framingham Offspring Study and the National Health and Nutrition Examination Survey 2001-2004. Diabetes Care. 2008;31(10):1991-1996.

34. Herman WH. Do race and ethnicity impact hemoglobin A1c independent of glycemia? J Diabetes Sci Technol. 2009;3(4):656-660.

35. Sacks DB, Bruns DE, Goldstein DE, Maclaren NK, McDonald JM, Parrott M. Guidelines and recommendations for laboratory analysis in the diagnosis and management of diabetes mellitus. Clin Chem. 2002;48(3):436-472. 
36. Radin MS. Pitfalls in hemoglobin A1c measurement: when results may be misleading. J Gen Intern Med. 2014;29(2):388-394.

37. Lee JE. Alternative biomarkers for assessing glycemic control in diabetes: fructosamine, glycated albumin, and 1,5-anhydroglucitol. Ann Pediatr Endocrinol Metab. 2015;20(2):74-78.

38. Malmström H, Walldius G, Grill V, Jungner I, Gudbjörnsdottir S, Hammar N. Fructosamine is a useful indicator of hyperglycaemia and glucose control in clinical and epidemiological studies--cross-sectional and longitudinal experience from the AMORIS cohort. PLoS One. 2014;9(10):e111463.

39. Bry L, Chen PC, Sacks DB. Effects of hemoglobin variants and chemically modified derivatives on assays for glycohemoglobin. Clin Chem. 2001;47(2):153-163.

40. Sacks DB, Arnold M, Bakris GL, et al. Guidelines and recommendations for laboratory analysis in the diagnosis and management of diabetes mellitus. Clin Chem. 2011;57(6):e1-e47.

41. Ribeiro RT, Macedo MP, Raposo JF. HbA1c, fructosamine, and glycated albumin in the detection of dysglycaemic conditions. Curr Diabetes Rev. 2016;12(1):14-19.

42. Austin GE, Wheaton R, Nanes MS, Rubin J, Mullins RE. Usefulness of fructosamine for monitoring outpatients with diabetes. Am J Med Sci. 1999;318(5):316-323.

43. Weerasekera DS, Peiris $\mathrm{H}$. The value of serum fructosamine in comparison with oral glucose tolerance test (OGTT) as a screening test for detection of gestational diabetes mellitus. J Obstet Gynaecol. 2000;20(2):136-138.

44. Schleicher ED, Olgemöller B, Wiedenmann E, Gerbitz KD. Specific glycation of albumin depends on its half-life. Clin Chem. 1993;39(4):625-628.

45. Selvin E, Francis LM, Ballantyne CM, et al. Nontraditional markers of glycemia: associations with microvascular conditions. Diabetes Care. 2011;34(4):960-967.

46. Rodríguez-Segade S, Rodríguez J, Camiña F. Corrected Fructosamine improves both correlation with $\mathrm{HbA1C}$ and diagnostic performance. Clin Biochem. 2017;50(3):110-115.

47. Chan CL, Pyle L, Kelsey M, Newnes L, Zeitler PS, Nadeau KJ. Screening for type 2 diabetes and prediabetes in obese youth: evaluating alternate markers of glycemia - 1,5-anhydroglucitol, fructosamine, and glycated albumin. Pediatr Diabetes. 2016;17(3):206-211.

48. Malkan UY, Gunes G, Corakci A. Rational diagnoses of diabetes: the comparison of 1,5-anhydroglucitol with other glycemic markers. Springerplus. 2015;4:587.

49. Sumner AE, Duong MT, Aldana PC, et al. A1C combined with glycated albumin improves detection of prediabetes in Africans: the Africans in America Study. Diabetes Care. 2016;39(2):271-277.

50. Danese E, Montagnana M, Nouvenne A, Lippi G. Advantages and pitfalls of fructosamine and glycated albumin in the diagnosis and treatment of diabetes. J Diabetes Sci Technol. 2015;9(2):169-176.

51. Selvin E, Rawlings AM, Grams M, et al. Prognostic utility of fructosamine and glycated albumin for incident diabetes and microvascular complications. Lancet Diabetes Endocrinol. 2014;2(4):279-288.

52. Wu WC, Ma WY, Wei JN, et al. Serum glycated albumin to guide the diagnosis of diabetes mellitus. PLoS One. 2016;11(1):e0146780.

53. Furusyo N, Koga T, Ai M, et al. Utility of glycated albumin for the diagnosis of diabetes mellitus in a Japanese population study: results from the Kyushu and Okinawa Population Study (KOPS). Diabetologia. 2011;54(12):3028-3036.

54. Selvin E, Rawlings AM, Lutsey PL, et al. Fructosamine and glycated albumin and the risk of cardiovascular outcomes and death. Circulation. 2015;132(4):269-277.

55. Shima K, Abe F, Chikakiyo H, Ito N. The relative value of glycated albumin, hemoglobin A1c and fructosamine when screening for diabetes mellitus. Diabetes Res Clin Pract. 1989;7(4):243-250.

56. Okada T, Nakao T, Matsumoto H, Yamanaka T, Nagaoka Y, Tamekuni T. Influence of age and nutritional status on glycated albumin values in hemodialysis patients. Intern Med. 2009;48(17):1495-1499.
57. Bulló M, García-Lorda P, Megias I, Salas-Salvadó J. Systemic inflammation, adipose tissue tumor necrosis factor, and leptin expression. Obesity Res. 2003;11(4):525-531.

58. Koga M, Hirata T, Kasayama S, Ishizaka Y, Yamakado M. Body mass index negatively regulates glycated albumin through insulin secretion in patients with type 2 diabetes mellitus. Clin Chim Acta. 2015;438:19-23

59. Ma XJ, Pan JM, Bao YQ, et al. Combined assessment of glycated albumin and fasting plasma glucose improves the detection of diabetes in Chinese subjects. Clin Exp Pharmacol Physiol. 2010;37(10):974-979.

60. Buse JB, Freeman JL, Edelman SV, Jovanovic L, McGill JB. Serum 1,5-anhydroglucitol (GlycoMark): a short-term glycemic marker. Diabetes Technol Ther. 2003;5(3):355-363.

61. Yamanouchi T, Akanuma Y. Serum 1,5-anhydroglucitol (1,5 AG): new clinical marker for glycemic control. Diabetes Res Clin Pract. 1994;24 Suppl:S261-S268.

62. Yamanouchi T, Akanuma H, Nakamura T, Akaoka I, Akanuma Y. Reduction of plasma 1,5-anhydroglucitol (1-deoxyglucose) concentration in diabetic patients. Diabetologia. 1988;31(1):41-45.

63. Yamanouchi T, Minoda S, Yabuuchi M, et al. Plasma 1,5-anhydro-Dglucitol as new clinical marker of glycemic control in NIDDM patients. Diabetes. 1989;38(6):723-729.

64. Wang Y, Yuan Y, Zhang Y, et al. Serum 1,5-anhydroglucitol level as a screening tool for diabetes mellitus in a community-based population at high risk of diabetes. Acta Diabetol. 2017;54(5):425-431.

65. Kim WJ, Park CY. 1,5-Anhydroglucitol in diabetes mellitus. Endocrine. 2013;43(1):33-40.

66. Balis DA, Tong C, Meininger G. Effect of canagliflozin, a sodiumglucose cotransporter 2 inhibitor, on measurement of serum 1,5-anhydroglucitol. J Diabetes. 2014;6(4):378-380.

67. Hasslacher C, Kulozik F. Effect of renal function on serum concentration of 1,5-anhydroglucitol in type 2 diabetic patients in chronic kidney disease stages I-III: a comparative study with $\mathrm{HbA} 1 \mathrm{c}$ and glycated albumin. J Diabetes. 2016;8(5):712-719.

68. Tabák AG, Carstensen M, Witte DR, et al. Adiponectin trajectories before type 2 diabetes diagnosis: Whitehall II study. Diabetes Care. 2012;35(12):2540-2547.

69. Jiang Y, Owei I, Wan J, Ebenibo S, Dagogo-Jack S. Adiponectin levels predict prediabetes risk: the Pathobiology of Prediabetes in A Biracial Cohort (POP-ABC) study. BMJ Open Diabetes Res Care. 2016;4(1):e000194.

70. Stefan N, Sun Q, Fritsche A, et al. Impact of the adipokine adiponectin and the hepatokine fetuin- $\mathrm{A}$ on the development of type 2 diabetes: prospective cohort- and cross-sectional phenotyping studies. PLoS One. 2014;9(3):e92238.

71. Pal D, Dasgupta S, Kundu R, et al. Fetuin-A acts as an endogenous ligand of TLR4 to promote lipid-induced insulin resistance. Nat Med. 2012;18(8):1279-1285.

72. Sun Q, Jiménez MC, Townsend MK, et al. Plasma levels of fetuin-A and risk of coronary heart disease in US women: the Nurses' Health Study. J Am Heart Assoc. 2014;3(3):e000939.

73. Weikert C, Stefan N, Schulze MB, et al. Plasma fetuin-a levels and the risk of myocardial infarction and ischemic stroke. Circulation. 2008;118(24):2555-2562.

74. Aroner SA, St-Jules DE, Mukamal KJ, et al. Fetuin-A, glycemic status, and risk of cardiovascular disease: The Multi-Ethnic Study of Atherosclerosis. Atherosclerosis. 2016;248:224-229.

75. Felig P, Marliss E, Cahill GF Jr. Plasma amino acid levels and insulin secretion in obesity. N Engl J Med. 1969;281(15):811-816.

76. Gall WE, Beebe K, Lawton KA, et al; RISC Study Group. alphahydroxybutyrate is an early biomarker of insulin resistance and glucose intolerance in a nondiabetic population. PLoS One. 2010;5(5): e10883.

77. Newgard CB, An J, Bain JR, et al. A branched-chain amino acid-related metabolic signature that differentiates obese and lean humans and contributes to insulin resistance. Cell Metab. 2009;9(4):311-326. 
78. Huffman KM, Shah SH, Stevens RD, et al. Relationships between circulating metabolic intermediates and insulin action in overweight to obese, inactive men and women. Diabetes Care. 2009;32(9): 1678-1683.

79. Chen T, NiY, Ma X, et al. Branched-chain and aromatic amino acid profiles and diabetes risk in Chinese populations. Sci Rep. 2016;6:20594.

80. Knebel B, Strassburger K, Szendroedi J, et al; German Diabetes Study Group. Specific metabolic profiles and their relationship to insulin resistance in recent-onset type 1 and type 2 diabetes. J Clin Endocrinol Metab. 2016;101(5):2130-2140.

81. Wang TJ, Ngo D, Psychogios N, et al. 2-Aminoadipic acid is a biomarker for diabetes risk. J Clin Invest. 2013;123(10):4309-4317.

82. Wang TJ, Larson MG, Vasan RS, et al. Metabolite profiles and the risk of developing diabetes. Nat Med. 2011;17(4):448-453.

83. El-Khairy L, Ueland PM, Nygård O, Refsum H, Vollset SE. Lifestyle and cardiovascular disease risk factors as determinants of total cysteine in plasma: the Hordaland Homocysteine Study. Am J Clin Nutr. 1999;70(6):1016-1024.

84. Wang-Sattler R, Yu Z, Herder C, et al. Novel biomarkers for prediabetes identified by metabolomics. Mol Syst Biol. 2012;8:615.

85. Guasch-Ferré M, Hruby A, Toledo E, et al. Metabolomics in prediabetes and diabetes: a systematic review and meta-analysis. Diabetes Care. 2016;39(5):833-846.

86. Sekhar RV, McKay SV, Patel SG, et al. Glutathione synthesis is diminished in patients with uncontrolled diabetes and restored by dietary supplementation with cysteine and glycine. Diabetes Care. 2011;34(1):162-167.

87. Fiehn O, Garvey WT, Newman JW, Lok KH, Hoppel CL, Adams $\mathrm{SH}$. Plasma metabolomic profiles reflective of glucose homeostasis in non-diabetic and type 2 diabetic obese African-American women. PLoS One. 2010;5(12):e15234.

88. Landaas $\mathrm{S}$. The formation of 2-hydroxybutyric acid in experimental animals. Clin Chim Acta. 1975;58(1):23-32.

89. Rosalki SB, Wilkinson JH. Reduction of alpha-ketobutyrate by human serum. Nature. 1960;188:1110-1111.

90. Lord RS, Bralley JA. Clinical applications of urinary organic acids. Part I: Detoxification markers. Altern Med Rev. 2008;13(3): 205-215.

91. Cobb J, Eckhart A, Motsinger-Reif A, Carr B, Groop L, Ferrannini E. $\alpha$-Hydroxybutyric acid is a selective metabolite biomarker of impaired glucose tolerance. Diabetes Care. 2016;39(6):988-995.

92. Cunningham TJ, Yao L, Lucena A. Product inhibition of secreted phospholipase A2 may explain lysophosphatidylcholines' unexpected therapeutic properties. J Inflamm (Lond). 2008;5:17.

93. Cobb J, Gall W, Adam KP, et al. A novel fasting blood test for insulin resistance and prediabetes. J Diabetes Sci Technol. 2013;7(1): 100-110.

94. Dotevall A, Johansson S, Wilhelmsen L, Rosengren A. Increased levels of triglycerides, BMI and blood pressure and low physical activity increase the risk of diabetes in Swedish women. A prospective 18-year follow-up of the BEDA study. Diabet Med. 2004;21(6):615-622.

95. Ding L, Song A, Dai M, et al. Serum lipoprotein (a) concentrations are inversely associated with $\mathrm{T} 2 \mathrm{D}$, prediabetes, and insulin resistance in a middle-aged and elderly Chinese population. J Lipid Res. 2015;56(4):920-926.

96. Shimodaira M, Niwa T, Nakajima K, Kobayashi M, Hanyu N, Nakayama T. Serum triglyceride levels correlated with the rate of change in insulin secretion over two years in prediabetic subjects. Ann Nutr Metab. 2014;64(1):38-43.

97. Filippatos TD, Rizos EC, Tsimihodimos V, Gazi IF, Tselepis AD, Elisaf MS. Small high-density lipoprotein (HDL) subclasses are increased with decreased activity of HDL-associated phospholipase A2 in subjects with prediabetes. Lipids. 2013;48(6):547-555.

98. Meikle PJ, Wong G, Barlow CK, et al. Plasma lipid profiling shows similar associations with prediabetes and type 2 diabetes. PLoS One. 2013;8(9):e74341.
99. Haus JM, Kashyap SR, Kasumov T, et al. Plasma ceramides are elevated in obese subjects with type 2 diabetes and correlate with the severity of insulin resistance. Diabetes. 2009;58(2):337-343.

100. Summers SA. Ceramides in insulin resistance and lipotoxicity. Prog Lipid Res. 2006;45(1):42-72.

101. Holland WL, Summers SA. Sphingolipids, insulin resistance, and metabolic disease: new insights from in vivo manipulation of sphingolipid metabolism. Endocr Rev. 2008;29(4):381-402.

102. Jiang XC, Paultre F, Pearson TA, et al. Plasma sphingomyelin level as a risk factor for coronary artery disease. Arterioscler Thromb Vasc Biol. 2000;20(12):2614-2618.

103. Aregbesola A, Virtanen JK, Voutilainen S, et al. Serum ferritin and glucose homeostasis: change in the association by glycaemic state. Diabetes Metab Res Rev. 2015;31(5):507-514.

104. Sharifi F, Nasab NM, Zadeh HJ. Elevated serum ferritin concentrations in prediabetic subjects. Diab Vasc Dis Res. 2008;5(1):15-18.

105. Cooksey RC, Jones D, Gabrielsen S, et al. Dietary iron restriction or iron chelation protects from diabetes and loss of beta-cell function in the obese (ob/ob lep-/-) mouse. Am J Physiol Endocrinol Metab. 2010;298(6):E1236-E1243.

106. Huang J, Jones D, Luo B, et al. Iron overload and diabetes risk: a shift from glucose to Fatty Acid oxidation and increased hepatic glucose production in a mouse model of hereditary hemochromatosis. Diabetes. 2011;60(1):80-87.

107. Zacharski LR, Ornstein DL, Woloshin S, Schwartz LM. Association of age, sex, and race with body iron stores in adults: analysis of NHANES III data. Am Heart J. 2000;140(1):98-104.

108. Dobó J, Schroeder V, Jenny L, Cervenak L, Závodszky P, Gál P. Multiple roles of complement MASP-1 at the interface of innate immune response and coagulation. Mol Immunol. 2014;61(2):69-78.

109. von Toerne C, Huth C, de Las Heras Gala T, et al. MASP1, THBS1, GPLD1 and ApoA-IV are novel biomarkers associated with prediabetes: the KORA F4 study. Diabetologia. 2016;59(9):1882-1892.

110. Lawler J. The functions of thrombospondin-1 and-2. Curr Opin Cell Biol. 2000;12(5):634-640.

111. Hoener MC, Brodbeck U. Phosphatidylinositol-glycan-specific phospholipase $\mathrm{D}$ is an amphiphilic glycoprotein that in serum is associated with high-density lipoproteins. Eur J Biochem. 1992;206(3):747-757.

112. Wang F, Kohan AB, Lo CM, Liu M, Howles P, Tso P. Apolipoprotein A-IV: a protein intimately involved in metabolism. J Lipid Res. 2015;56(8):1403-1418.

113. Green PH, Glickman RM, Riley JW, Quinet E. Human apolipoprotein A-IV: Intestinal origin and distribution in plasma. J Clin Invest. 1980;65(4):911-919.

114. Eaton S. Control of mitochondrial beta-oxidation flux. Prog Lipid Res. 2002;41(3):197-239.

115. Ramsay RR, Gandour RD, van der Leij FR. Molecular enzymology of carnitine transfer and transport. Biochim Biophys Acta. 2001;1546(1):21-43.

116. Zhang X, Zhang C, Chen L, Han X, Ji L. Human serum acylcarnitine profiles in different glucose tolerance states. Diabetes Res Clin Pract. 2014;104(3):376-382.

117. Mai M, Tönjes A, Kovacs P, Stumvoll M, Fiedler GM, Leichtle AB Serum levels of acylcarnitines are altered in prediabetic conditions PLoS One. 2013;8(12):e82459.

118. Adams SH, Hoppel CL, Lok KH, et al. Plasma acylcarnitine profiles suggest incomplete long-chain fatty acid beta-oxidation and altered tricarboxylic acid cycle activity in type 2 diabetic African-American women. J Nutr. 2009;139(6):1073-1081

119. Al-Kafaji G, Al-Mahroos G, Alsayed NA, Hasan ZA, Nawaz S, Bakhiet M. Peripheral blood microRNA-15a is a potential biomarker for type 2 diabetes mellitus and pre-diabetes. Mol Med Rep. 2015;12(5): 7485-7490.

120. Párrizas M, Brugnara L, Esteban Y, et al. Circulating miR-192 and miR-193b are markers of prediabetes and are modulated by an exercise intervention. J Clin Endocrinol Metab. 2015;100(3):E407-E415. 
121. Yang Z, Chen H, Si H, et al. Serum miR-23a, a potential biomarker for diagnosis of pre-diabetes and type 2 diabetes. Acta Diabetol. 2014;51(5):823-831.

122. Sun L, Xie H, Mori MA, et al. Mir193b-365 is essential for brown fat differentiation. Nat Cell Biol. 2011;13(8):958-965.

123. Zelber-Sagi S, Lotan R, Shibolet O, et al. Non-alcoholic fatty liver disease independently predicts prediabetes during a 7-year prospective follow-up. Liver Int. 2013;33(9):1406-1412.

124. Kong L, Zhu J, Han W, et al. Significance of serum microRNAs in pre-diabetes and newly diagnosed type 2 diabetes: a clinical study. Acta Diabetol. 2011;48(1):61-69.

125. Liu Y, Gao G, Yang C, et al. The role of circulating microRNA-126 (miR-126): a novel biomarker for screening prediabetes and newly diagnosed type 2 diabetes mellitus. Int J Mol Sci. 2014;15(6): 10567-10577.

126. Sun LL, Jiang BG, Li WT, Zou JJ, Shi YQ, Liu ZM. MicroRNA15 a positively regulates insulin synthesis by inhibiting uncoupling protein-2 expression. Diabetes Res Clin Pract. 2011;91(1):94-100.

127. Maschirow L, Khalaf K, Al-Aubaidy HA, Jelinek HF. Inflammation, coagulation, endothelial dysfunction and oxidative stress in prediabetes--Biomarkers as a possible tool for early disease detection for rural screening. Clin Biochem. 2015;48(9):581-585.

128. Arora P, Garcia-Bailo B, Dastani Z, et al. Genetic polymorphisms of innate immunity-related inflammatory pathways and their association with factors related to type 2 diabetes. BMC Med Genet. 2011;12:95.

129. Donath MY, Shoelson SE. Type 2 diabetes as an inflammatory disease. Nat Rev Immunol. 2011;11(2):98-107.

130. Schmidt MI, Duncan BB, Sharrett AR, et al. Markers of inflammation and prediction of diabetes mellitus in adults (Atherosclerosis Risk in Communities study): a cohort study. Lancet. 1999;353(9165):1649-1652.

131. Pradhan AD, Manson JE, Rifai N, Buring JE, Ridker PM. C-reactive protein, interleukin 6 , and risk of developing type 2 diabetes mellitus. JAMA. 2001;286(3):327-334.

132. Festa A, Hanley AJ, Tracy RP, D’Agostino R Jr, Haffner SM. Inflammation in the prediabetic state is related to increased insulin resistance rather than decreased insulin secretion. Circulation. 2003;108(15):1822-1830.

133. van Woudenbergh GJ, Kuijsten A, Sijbrands EJ, Hofman A, Witteman JC, Feskens EJ. Glycemic index and glycemic load and their association with C-reactive protein and incident type 2 diabetes. J Nutr Metab. 2011;2011:623076.

134. Grossmann V, Schmitt VH, Zeller T, et al. Profile of the immune and inflammatory response in individuals with prediabetes and type 2 diabetes. Diabetes Care. 2015;38(7):1356-1364.

135. Dehghan A, Kardys I, de Maat MP, et al. Genetic variation, C-reactive protein levels, and incidence of diabetes. Diabetes. 2007;56(3): 872-878.

136. Wang Z, Shen XH, Feng WM, Ye GF, Qiu W, Li B. Analysis of inflammatory mediators in prediabetes and newly diagnosed type 2 diabetes patients. J Diabetes Res. 2016;2016:7965317.

137. Wang X, Bao W, Liu J, et al. Inflammatory markers and risk of type 2 diabetes: a systematic review and meta-analysis. Diabetes Care. 2013;36(1):166-175.

138. McLaughlin T, Abbasi F, Lamendola C, et al. Differentiation between obesity and insulin resistance in the association with C-reactive protein. Circulation. 2002;106(23):2908-2912.

139. Madjid M, Awan I, Willerson JT, Casscells SW. Leukocyte count and coronary heart disease: implications for risk assessment. J Am Coll Cardiol. 2004;44(10):1945-1956.

140. Vozarova B, Weyer C, Lindsay RS, Pratley RE, Bogardus C, Tataranni PA. High white blood cell count is associated with a worsening of insulin sensitivity and predicts the development of type 2 diabetes. Diabetes. 2002;51(2):455-461.
141. Mertoglu C, Gunay M. Neutrophil-Lymphocyte ratio and PlateletLymphocyte ratio as useful predictive markers of prediabetes and diabetes mellitus. Diabetes Metab Syndr. Epub 2016 Dec 12.

142. Wang RT, Zhang JR, Li Y, Liu T, Yu KJ. Neutrophil-Lymphocyte ratio is associated with arterial stiffness in diabetic retinopathy in type 2 diabetes. J Diabetes Complications. 2015;29(2):245-249.

143. Verdoia M, Schaffer A, Barbieri L, et al; Novara Atherosclerosis Study Group (NAS). Impact of diabetes on neutrophil-to-lymphocyte ratio and its relationship to coronary artery disease. Diabetes Metab. 2015;41(4):304-311.

144. Demirtas L, Degirmenci H, Akbas EM, et al. Association of hematological indicies with diabetes, impaired glucose regulation and microvascular complications of diabetes. Int J Clin Exp Med. 2015;8(7): 11420-11427.

145. Bardini G, Dicembrini I, Cresci B, Rotella CM. Inflammation markers and metabolic characteristics of subjects with 1-h plasma glucose levels. Diabetes Care. 2010;33(2):411-413.

146. Fiorentino TV, Hribal ML, Perticone M, et al. Unfavorable inflammatory profile in adults at risk of type 2 diabetes identified by hemoglobin A1c levels according to the American Diabetes Association criteria. Acta Diabetol. 2015;52(2):349-356.

147. Festa A, D’Agostino R Jr, Tracy RP, Haffner SM, Insulin Resistance Atherosclerosis Study. Elevated levels of acute-phase proteins and plasminogen activator inhibitor-1 predict the development of type 2 diabetes: the insulin resistance atherosclerosis study. Diabetes. 2002;51(4):1131-1137.

148. Festa A, D’Agostino R Jr, Mykkänen L, et al. Relative contribution of insulin and its precursors to fibrinogen and PAI-1 in a large population with different states of glucose tolerance. The Insulin Resistance Atherosclerosis Study (IRAS). Arterioscler Thromb Vasc Biol. 1999;19(3):562-568.

149. Thorand B, Kolb H, Baumert J, et al. Elevated levels of interleukin-18 predict the development of type 2 diabetes: results from the MONICA/KORA Augsburg Study, 1984-2002. Diabetes. 2005;54(10): 2932-2938.

150. Donath MY. Inflammation as a sensor of metabolic stress in obesity and type 2 diabetes. Endocrinology. 2011;152(11):4005-4006.

151. Carstensen M, Herder C, Kivimäki M, et al. Accelerated increase in serum interleukin-1 receptor antagonist starts 6 years before diagnosis of type 2 diabetes: Whitehall II prospective cohort study. Diabetes. 2010;59(5):1222-1227.

152. Bergman M, Jagannathan R, Buysschaert M, et al. Reducing the prevalence of dysglycemia: is the time ripe to test the effectiveness of intervention in high-risk individuals with elevated $1 \mathrm{~h}$ post-load glucose levels? Endocrine. 2017;55(3):697-701.

153. Bergman M. The Early Diabetes Intervention Program--is early actually late? Diabetes Metab Res Rev. 2014;30(8):654-658.

154. Bueno AC, Sun K, Martins CS, et al. A novel ADIPOQ mutation (p.M40K) impairs assembly of high-molecular-weight adiponectin and is associated with early-onset obesity and metabolic syndrome. J Clin Endocrinol Metab. 2014;99(4):E683-E693.

155. Aekplakorn W, Tantayotai V, Numsangkul S, et al. Detecting Prediabetes and Diabetes: Agreement between Fasting Plasma Glucose and Oral Glucose Tolerance Test in Thai Adults. J Diabetes Res. 2015;2015:396505.

156. Gall WE, Beebe K, Lawton KA, et al. alpha-hydroxybutyrate is an early biomarker of insulin resistance and glucose intolerance in a nondiabetic population. PLoS One. 2010;5(5):e10883.

157. Suzuki T, Imai J, Yamada T, et al. Interleukin-6 enhances glucosestimulated insulin secretion from pancreatic beta-cells: potential involvement of the PLC-IP3-dependent pathway. Diabetes. 2011;60(2):537-547.

158. Kim JH, Bachmann RA, Chen J. Interleukin-6 and insulin resistance. Vitam Horm. 2009;80:613-633. 
Diabetes, Metabolic Syndrome and Obesity: Targets and Therapy

Diabetes, Metabolic Syndrome and Obesity: Targets and Therapy is an international, peer-reviewed open-access journal committed to the rapid publication of the latest laboratory and clinical findings in the fields of diabetes, metabolic syndrome and obesity research. Original research, review, case reports, hypothesis formation, expert opinion and commentaries are all considered for publication. The manuscript management system is completely online and includes a very quick and fair peer-review system, which is all easy to use. Visit http://www.dovepress.com/testimonials.php to read real quotes from published authors.

Submit your manuscript here: https://www.dovepress.com/diabetes-metabolic-syndrome-and-obesity-targets-and-therapy-journal 